\title{
EXPERIMENTAL STUDY OF THE PHENOMENON OF MICROORGANISM-ASSOCIATED
} CRYSTALLOGENESIS

Received 4 March 2021; Received in revised form 15 April 2021: Accepted 20 April 2021

\section{Andrew Martusevich ${ }^{1,2 \otimes} \mathbb{B}^{\mathbb{D}}$, Ivan Bocharin ${ }^{1,2}(\mathrm{D})$, Maxim Guryanov' ${ }^{10}$, Alexei Kochkurov' ${ }^{1}$, Elena Kochkurova ${ }^{1,3}{ }^{(D)}$, Marina Ivashchenko ${ }^{2}$}

\author{
'Privolzhsky Research Medical University, Nizhny Novgorod; \\ ${ }^{2}$ Nizhny Novgorod State Agricultural Academy, Nizhny Novgorod; \\ ${ }^{3}$ N. I. Lobachevsky State University of Nizhny Novgorod, Nizhny Novgorod, \\ Russia
}

cryst-mart@yandex.ru
ABSTRACT - THE AIM OF THE STUDY was to clarify the character of the initiatory activity of pathogenic and nonpathogenic microorganisms in regard to salt solutions. We selected colonies of two microorganisms: Escherichia coli (E. coli) and Staphylococcus aureus (St. aureus) $\left[10^{6}, 10^{8}\right.$, $10^{10}, 10^{12}, 10^{14}, 10^{16}, 10^{18}$ and $10^{20} \mathrm{CFU} / \mathrm{ml}$ of solution]. A $10 \%$ solution of sodium chloride was used as the initiated substance, which made it possible to perform a tezigraphic test. On the basis of model experiments with colonies of some pathogenic and non-pathogenic microorganisms, a new phenomenon was confirmed - microbial initiation of crystal formation (the phenomenon of microorganismassociated crystallogenesis). This phenomenon is universal for microagents, but it also has specific features imposed by the species of the microorganism and its current functional state.

KEYW ORDS - biocrystallomics, microorganism-associated crystallogenesis, Staphylococcus, Escherichia.

\section{INTRODUCTION}

The metabolic activity of various microorganisms is widely discussed in the literature. At the same time, various properties of bacteria are studied and applied in some industries $[1,2,6,7]$. In these works, numerous facts of the connection of the processes of crystal formation with the activity of microbes are presented. The most studied are representatives of the genus Pseudumonas, which are able to initiate the crystallogenesis of various organic and mineral compounds from solutions $[1,2,5]$. Similar properties were found in other microorganisms (Listeria innocua, Escherichia coli, Helicobacter pylori, Desulfovibrio desulfuricans, Agrobacterium tumefaciens $[1-3,5]$ etc.). A significant practical interest is the ability of microorganisms to accumulate many metals, including noble metals (gold, silver, platinum) in the form of microcrystals in the perimembrane space or intracellularly $[1,2,6,7]$.

Thus, the aim of the study was to clarify the character of the initiatory activity of pathogenic and non-pathogenic microorganisms in regard to salt solutions.

\section{MATERIAL AND METHODS}

We selected colonies of two microorganisms: Escherichia coli (E. coli) and Staphylococcus aureus (St. aureus). Tthe strains were obtained at the Kirov Research Institute of Hematology and Blood Transfusion. In order to clarify the role of the concentration of the bacterium, the same test amounts of bacteria were used for both microorganisms: $10^{6}, 10^{8}, 10^{10}, 10^{12}$, $10^{14}, 10^{16}, 10^{18}$ and $10^{20} \mathrm{CFU} / \mathrm{ml}$ of solution. A $10 \%$ solution of sodium chloride was used as an initiated substance, which made it possible to perform a tezigraphic test [4]. This allowed to quantify the initiatory potential of the bacteria - the ability to influence the crystallization pattern of the salt solution. Statistical processing of the results was performed using variation statistics algorithms, Microsoft Excel 2007 and Statistica 6.1 for Windows.

\section{RESULTS}

The study of crystallogenic properties of $10 \%$ sodium chloride solution has allowed to establish that there is a dynamics accelerating the expressiveness of shifts in crystal formation of hypertonic saline with an increase in the content of microagent. It is important that this trend applies to both micro-organisms. A more detailed study of the distribution of tezigrams along the line of the increasing initiating dose of the microagent, taking into account all controlled concentrations, revealed a two-stage nature of the reaction of sodium chloride on the metabolic activity of the microorganism. It includes the initial absence of significant variations compared to the reference sample of the reference substance. As the number of microbial bodies increases, a concentration for each microorganism is clearly recorded, which initiates the dynamics of crystallogenesis transformation in the marginal zone. It is expressed in the formation of islands of single crystals surrounding relatively large pyramidal structures formed by sodium chloride. It is essential that the 
concentration, at which such changes are detected in Escherichia and Staphylococcus, varies, and it is significantly less in the pathogenic microagent. Thus, for E. coli, this threshold concentration is $10^{12} \mathrm{CFU} / \mathrm{ml}$, while for St. Aureus, even with the minimum (of the studied) number of bacteria $\left(10^{6} \mathrm{CFU} / \mathrm{ml}\right)$, significant transformations of the structure of the marginal zone are registered.

The third of the variants of initiation of sodium chloride crystallization by bacteria associated with the number of micro-agents identified by us is the increasing neocrystallogenesis in the central and intermediate zones of the dried samples. Based on this, it is possible to distinguish the second threshold concentration, and its values species-specific $\left(10^{14} \mathrm{CFU} / \mathrm{ml}\right.$ for $\mathrm{E}$. coli and $10^{10} \mathrm{CFU} / \mathrm{ml}$ for S. aureus).

In accordance with the chosen method of describing dried samples, we performed not only a qualitative, but also a quantitative assessment by applying a system of criteria. The analysis showed that the qualitative transformations associated with the metabolic activity of bacteria are fully confirmed when evaluating the quantitative criteria of the diagnostic test. In particular, the monotonous increase in the level of the main tezigraphic coefficient is the result of first marginal, and then total (extending to all zones of the facia) neocrystallogenesis, reflecting the initiator potential of the microorganism. At the same time, the increase in the number of crystal structures is not accompanied by an increase in structure index. Thus, in terms of the main tezigraphic coefficient, and, consequently, in terms of the initiatory capacity (when using a 10\% sodium chloride solution as a base substance), St. aureus significantly surpasses E. coli at all the studied concentrations $(\mathrm{p}<0.05)$, and if the initiatory potential of E. coli is insignificant at small values, then it is initially high in staphylococci (increased crystal formation of sodium chloride by 3.5 times). At high concentrations, the clear differentiation between bacteria is somewhat smoothed out due to a pronounced increase in the initiator potential of E. coli.

Similar trends were found when assessing the correctness of the crystallogenesis of the sodium chloride solution modulated by microorganisms (according to facia destruction degree), but no significant differences were at low concentrations of bacterial agents $(\mathrm{p}<0.05)$. In addition, a pathogenic bacterium (in our case, Staphylococcus aureus) at medium and high concentrations has a fairly clear destructive effect on the crystallization of sodium chloride solutions than an Escherichia coli. These changes are verified by correlation analysis $(\mathrm{r}=-0.103 \pm 0.062)$.

\section{CONCLUSION}

On the basis of model experiments with colonies of some pathogenic and non-pathogenic microorganisms, a new phenomenon was confirmed - microbial initiation of crystal formation (the phenomenon of microorganism-associated crystallogenesis). This phenomenon is universal for microagents, but it also has specific features imposed by the species of the microorganism and its current functional state.

\section{REFERENCES}

1. Dieudonné A., Pignol D., Prévéral S. Magnetosomes: biogenic iron nanoparticles produced by environmental bacteria // Appl Microbiol Biotechnol. - 2019 Vol. 103, N9. - P. 3637-3649. doi: 10.1007/ s00253-019-09728-9.

2. Faivre D., Godec T.U. From bacteria to mollusks: the principles underlying the biomineralization of iron oxide materials // Angew Chem Int Ed Engl. 2015. - Vol. 54, N 16. - P. 4728-4747. doi: 10.1002/ anie. 201408900 .

3. Garate L., Sureda J, Agell G, Uriz MJ. Endosymbiotic calcifying bacteria across sponge species and oceans // Sci Rep. - 2017. - Vol. 7. - 43674. doi: $10.1038 /$ srep 43674 .

4. Martusevich A.K., Kamakin N.F. Unified algorithm for the study of free and initiated crystallogenesis of biological fluids / Clinical laboratory diagnostics. - 2007. - No. 6. - P. 21-24.

5. McCausland HC, Komeili A. Magnetic genes: Studying the genetics of biomineralization in magnetotactic bacteria // PLoS Genet. - 2020. - Vol. 16, N 2. - e1008499. doi: 10.1371/journal.pgen.1008499.

6. Zhang K, Xue Y, Zhang J, Hu X. Removal of lead from acidic wastewater by bio-mineralized bacteria with $\mathrm{pH}$ self-regulation // Chemosphere. - 2020. - Vol. 241. - 125041. doi: 10.1016/j.chemosphere.2019.125041.

7. Zhao X, Wang M, Wang H, Tang D, Huang J, Sun Y. Study on the Remediation of Cd Pollution by the Biomineralization of Urease-Producing Bacteria // Int J Environ Res Public Health. - 2019. - Vol. 16, N 2. - 268. doi: 10.3390/ijerph16020268. 